\title{
Las columnas de la lengua sobre comunicación política del Marqués de Tamarón y Álex Grijelmo: la "lengua" de los políticos en cuestión $^{1}$
}

\author{
Language columns about political \\ communication of Marqués de Tamarón and \\ Álex Grijelmo: the "language" of politians in \\ question
}

\author{
Carmen Sánchez Manzanares \\ Universidad de Murcia, Murcia, España \\ carmensm@um.es
}

\section{Resumen}

El objetivo de este artículo es indagar en el análisis de la comunicación política que se realiza en las columnas sobre la lengua publicadas en diarios españoles después del período político conocido como la transición. Para ello, hemos seleccionado a dos columnistas, el Marqués de Tamarón y Álex Grijelmo, que escriben, respectivamente, en los años ochenta del siglo XX y en las primeras décadas del siglo XXI. Hemos examinado el tratamiento que realizan de los recursos y estrategias señalados en los estudios críticos del discurso y la pragmática lingüística para la caracterización de los usos políticos del lenguaje. Los resultados de nuestro análisis muestran que el Marqués de Tamarón opta por una caracterización sociológica del habla "incorrecta" de los políticos, mientras que el interés de Grijelmo es la legitimidad del discurso de los actores políticos. Se concluye que la discusión lingüística que se presenta en sus columnas no está motivada únicamente por las finalidades propias del género metalingüístico al que se adscriben. El propósito es interpretar, en el caso del Marqués de Tamarón, los cambios sociales que inducen la jerga usada por los políticos, y, en el de Grijelmo, la manipulación de los acontecimientos políticos referidos en el discurso.

\footnotetext{
${ }^{1}$ Este trabajo se inscribe en el marco del Proyecto I+D+i PID2019-107265GB-I00 El columnismo lingüístico en la prensa española desde sus orígenes. Análisis multidimensional, caracterización y aplicaciones (METAPRES-COLING).
} 
Palabras clave: columna sobre la lengua, comunicación política, análisis del discurso, manipulación lingüística, incorrección lingüística.

\begin{abstract}
The objective of this paper is to investigate the analysis of political communication carried out in the columns on language published in Spanish newspapers after the political period known as the Transition. For this study, we have selected two columnists, the Marqués de Tamarón and Álex Grijelmo, who write, respectively, in the eighties of the twentieth century and in the first decades of the twenty-first. We have examined their treatment of the resources and strategies indicated in discourse analysis and linguistic pragmatics to characterize the political uses of language. The results of our analysis show that the Marqués de Tamarón opts for a sociological characterization of the "incorrect" speech of politicians, while Grijelmo is more interested in the legitimacy of the speech of political actors. We can conclude that the linguistic discussion presented in these columns is not solely motivated by the purposes of the metalinguistic genre to which they are assigned. In the case of the Marqués de Tamarón, the purpose is to interpret the social changes that induce jargon used by politicians, while in Grijelmo's case, it is the manipulation of the political events referred to in the discourse.
\end{abstract}

Keywords: columns on language, political communication, discourse analysis, linguistic manipulation, linguistic inaccuracy.

\title{
1. Introducción. Objetivos y metodología
}

En la columna sobre la lengua (CSL), desde sus inicios en la prensa española a finales del siglo $\mathrm{XIX}^{2}$, encontramos una actitud crítica ante el uso de la lengua que realizan determinados actores de la comunicación social. Así, este género periodístico opinativo ofrece un espacio textual a un tipo de discurso metalingüístico en el que no solo se divulgan o debaten normas de corrección o principios de comunicación, sino que también se cuestionan los modos de comunicación que se emplean en discursos de proyección pública. Por ello, en las columnas de la lengua de distintos firmantes se realiza una aproximación a aspectos que conciernen a la comunicación persuasiva y la ética del lenguaje, fundamentalmente, a la manipulación lingüística que ejercen políticos, periodistas y otros profesionales con alcance mediático. En el presente estudio nos proponemos indagar en el análisis de la comunicación política que se realiza en dos columnas sobre la lengua publicadas en diarios españoles después del período político conocido como la transición: la del marqués de Tamarón en $A B C$ y la de Álex Grijelmo en El País. Partimos de la hipótesis de que para deconstruir el discurso político y dar al lector pautas para una interpretación cabal, estos autores tratarán, principalmente, distintos recursos y estrategias señalados en los estudios del discurso y, en general, en los estudios de pragmática lingüística, con los que se pretende el encubrimiento o falseamiento de la información. Nuestra pregunta de

\footnotetext{
${ }^{2}$ Marimón (2019, p. 8) presenta la cronología de este tipo de columnas periodísticas en El columnismo lingüistico en España desde 1940 (2019), señalando su punto de inicio en los artículos de Antonio de Valbuena en el periódico El Imparcial en 1883 y registrando la nómina de autores principales hasta la actualidad.
} 
investigación es relativa tanto a la perspectiva del columnista en el tratamiento de los usos políticos del lenguaje, como a los propósitos que guían su interpretación del discurso político, más allá del análisis lingüístico.

La elección de la columna de Santiago de Mora-Figuera, Marqués de Tamarón, se debe al hecho de que este diplomático, que además es escritor, por su cercanía profesional a la clase política, aborda con frecuencia las actuaciones verbales de los políticos para contrastar su identidad ideológica e ironizar sobre su capacidad oratoria y su competencia lingüística, valorando, en una perspectiva sociológica, la oscuridad del lenguaje político. Sus artículos se publican en $A B C$ entre 1985 y 1988 en la columna que titula El habla nacional en un primer momento y después El guirigay nacional y son testimonio del período político en que España, ya integrada en la Comunidad Económica Europea, ha cerrado definitivamente la denominada transición, con un partido de izquierdas por primera vez en el gobierno después del franquismo. En cuanto a la selección de la columna de Grijelmo, La punta de la lengua, está motivada por acoger numerosos artículos en los que el periodista denuncia los engaños de la comunicación política. Se trata de una columna que se publica desde 2013 en el diario El País, pero comenzó en 2000 en el semanal de El diario de Valladolid, donde apareció hasta 2002. En varias entregas, Grijelmo, especialmente atento a las "trampas del lenguaje", se ocupa de la manipulación de lo referido en el discurso político mediante distintos recursos lingüísticos con los que se construye un discurso falaz. En definitiva, ambos valoran en muchas de sus CSL los usos y recursos que identifican en el habla de los políticos y muestran su posición crítica, por un lado, con respecto a la corrección lingüística, y por otro, con respecto a la precisión en la comunicación y la posverdad en la que se sitúan los políticos, que parece hallarse legitimada en el mismo ámbito de la política.

Por último, en estas CSL que analizamos podemos constatar la dimensión social de las CSL como testimonio del uso de la lengua en concretos contextos políticos de las últimas décadas del siglo XX y las primeras del siglo XXI, y con ello contrastar los usos que definen cada período siguiendo el método de "palabras e ideas" que después señalaremos. También posibilita un estudio prospectivo sobre el enjuiciamiento en cada época de las estrategias y recursos usados que permita contrastar las perspectivas adoptadas para cuestionar la "lengua" de los políticos y comprobar si las estrategias y recursos puestos en cuestión son o no recurrentes.

\section{La prensa ante las estrategias de la comunicación política}

Uno de los aspectos más tratados en el análisis de la comunicación política es el de la selección léxica en discurso para la construcción de la doxa u opinión pública mediante la creación de significados y la resolución de interdicciones que derivan de tabús sociales. En un análisis de las estrategias léxicas centrado en el políticohablante, Gallardo Paúls (2014) advierte que se llega a una paradoja enunciativa de orden léxico-ilocutivo mediante recursos léxicos y estrategias como los encuadres léxicos, intencionales y predicativos. Cuando trata el modo en que se somete el concepto político al equívoco y a la ambigüedad mediante el uso sesgado o impropio de términos, da cuenta del interés que despiertan estos usos en la prensa y en el seno mismo de la comunidad política:

La prensa se ha hecho eco repetidamente de estos excesos denominadores, especialmente acentuados en período al que pertenecen los datos que manejamos, en el que las escaramuzas de ocultamiento y camuflaje semántico parecen trasladar esas 
mismas ideas de tergiversación y escamoteo a la propia acción política; llama la atención, de hecho, la frecuencia con que, especialmente en 2013, la prensa se ha hecho eco de casos concretos en los que cierto político o cierto partido se pronunciaba explícitamente sobre la oportunidad de usar o no ciertos términos; "crisis", "rescate", "imputado", "desahucio", "escrache", "fuga de cerebros", "sobresueldo" son términos cuya definición ha ocupado el debate político, no el lexicográfico [...] (Gallardo Paúls, 2014, p. 60).

En efecto, observamos que los periodistas, atentos a los usos políticos del lenguaje, participan en un debate que se traslada desde el espacio mismo de la dialéctica política, pues en unos y otros partidos el uso de determinadas palabras por parte de los rivales se convierte en argumento para captar adeptos.

Especialmente se ha fijado la prensa en el eufemismo ${ }^{3}$ como recurso léxico "tramposo" para no nombrar lo que puede resultar polémico o lo que es tabú en el contexto político y social. Como Sánchez García (2018, p. 89) indica, los usos del eufemismo no responden únicamente al propósito de manipulación, pues intervienen lo que se conoce como lo políticamente correcto o la cortesía, pero en el caso de los usos políticos, los eufemismos suelen formar parte de estrategias manipuladoras o persuasivas ${ }^{4}$. Este autor señala que la prensa, al llamar la atención sobre el discurso oscuro y ambiguo que resulta al introducir eufemismos políticos, se convierte en altavoz de estos usos eufemísticos, que finalmente logran generalizarse (2018, p. 69), lo que explica a partir del concepto de marco cognitivo (frame) de la lingüística cognitiva. Nuestros columnistas a veces nos advierten sobre estos usos precisamente cuando ya se han generalizado, pero su papel sigue siendo crucial, puesto que nos alertan del riesgo de asumir como cierta lo que es una interpretación falaz. Así, cuando publica Palabras de doble filo (2015), libro que reúne las columnas publicadas en El País desde 2013 hasta el momento, Grijelmo concede una entrevista ${ }^{5}$ y muestra lo que consideramos una intención latente en sus columnas: una especie de aviso lingüístico para que no manipulen nuestra percepción de la realidad mediante palabras u omisiones:

Estoy acostumbrado a reflexionar sobre las palabras y hay determinadas manipulaciones que descubro ¡meses después de estar escuchándolas! Hay que combatir que, mediante estas manipulaciones lingüísticas, nos cambien nuestra percepción de la realidad. En la manipulación política, aparte de los eufemismos, me preocupan los "efectos de silencio", de lo que se calla no porque se omita el mensaje entero, sino porque dentro de un mensaje se omite una parte (Grijelmo, eldiario.es, 24/02/2015).

Gallardo Paúls (2014, p. 30) propone observar el encuadre o marco cognitivo del discurso político a partir de cinco estrategias lingüísticas que adscribe a tres niveles pragmáticos: A) Nivel enunciativo: 1) estrategia léxica o denominadora; 2) estrategia intencional; 3) estrategia predicativa; B) Nivel textual: 4) estrategia estructural; C) estrategia intertextual o dialógica. Como iremos mostrando a través del análisis de las columnas seleccionadas, nuestros columnistas desmontan la

\footnotetext{
${ }^{3}$ Remitimos a Casas (2012) para la definición y caracterización de este proceso cognitivo que se actualiza mediante una serie de mecanismos lingüísticos y cuya función es la de encubrimiento, atenuación o realce expresivo de un concepto interdicto.

${ }^{4}$ Como ha señalado Chamizo (2004, p. 45), para que en sincronía una palabra funcione como eufemismo, su interpretación debe ser ambigua, razón por la cual se explotan los usos eufemísticos en el discurso político.

${ }^{5}$ Puede accederse a la entrevista en el siguiente enlace: https://www.eldiario.es/cultura/alex-grijelmoprocuro-escribir-muchas_1_4365994.html
} 
estrategia estructural (argumentativa) del discurso político centrándose principalmente en sus estrategias en el nivel enunciativo.

En las CSL se tiene la característica de que, siendo los firmantes personas autorizadas por su cultura y, en la mayoría de los casos, por su profesión, confluyen el conocimiento de experto y el dominio de la opinión. Como así lo ha expuesto Charaudeau (1997, p. 97), la opinión implica un juicio de orden intelectivo, no afectivo, a favor o en contra de lo verosímil, que se apoya, no en lo universal, sino en un sistema de normas relativo a un contexto sociocultural, por lo que es un juicio sesgado. Por ello, los discursos de instancias como los medios de comunicación, la política y la ciudadanía, dependientes de sistemas de valores de los grupos sociales, dan significado a los acontecimientos de la realidad empírica que es el espacio público:

Une fois de plus, des morts sont des morts ; mais pour qu'ils signifient "génocide", "purification ethnique", " solution finale", "victimes de la destinée", il faut qu'ils s'insèrent dans des discours d'intelligibilité du monde, lesquels dépendent des groupes sociaux et des systèmes des valeurs qu'ils produisent. Autrement dit, pour que l'evenement existe, il faut le nommer. L'événement ne signifie pas en soi. L'événement ne signifie qu'en tant qu'il fait événement dans un discours. L'événement signifié naît dans un processus événementiel (Charaudeau, 1997, p. 146).

En las CSL que analizaremos el interés radica, por tanto, en que se cuestiona cómo se significan los acontecimientos por parte de la instancia política. Nuestro primer objetivo es analizar el enfoque de los columnistas frente a la comunicación política, para lo cual identificamos los recursos y estrategias de la comunicación política por los que se interesan y examinamos qué variables consideran para su interpretación. Como tendremos ocasión de mostrar, el Marqués de Tamarón parte de la observación de usos "incorrectos" -generalmente por imprecisos- por parte de los políticos para aventurar una causa sociológica o un condicionamiento ideológico. Mientras, Grijelmo se interesa principalmente por usos manipuladores para revelar el argumentario político subyacente. Aunque ambos focalizan en la precisión semántica de las palabras para analizar la significación discursiva, pretendemos mostrar su diferente perspectiva al cuestionar la "lengua" de los políticos. Un segundo objetivo de este trabajo es establecer la finalidad que pretende cada columnista en su análisis del habla de los políticos, lo que nos llevará a plantearnos determinadas cuestiones al respecto y con relación al interés del lector que se acerca a sus escritos.

\section{Dos columnistas ante la "lengua" de los políticos: el Marqués de Tamarón y Álex Grijelmo}

Santiago de Mora-Figueroa y Williams, noveno Marqués de Tamarón (Jerez de la Frontera, 1941), diplomático y escritor, director del Instituto Cervantes entre 1996 y 1999, culmina su carrera profesional como embajador de España para la Diplomacia Cultural, cargo que desempeñó desde 2012 hasta 2017. Entre 1985 y 1988 publica una columna en el diario $A B C$, titulada primeramente El habla nacional y después El guirigay nacional, como ya adelantamos. Este último título nos permite aventurar su actitud crítica y jocosa ante el habla de los "nativos" españoles, como queda constatado en el "Prefacio del autor" de la edición de 2006 
(corregida y aumentada) de El guirigay nacional (1988), libro en el que se recopilan estas columnas y algún escrito posterior:

Lo recuerdo muy bien, era un día de bochorno tropical cuando descubrí que no entendía a los nativos. Corría el verano de 1981 y yo acababa de volver a Madrid tras catorce años de ausencia. Los nativos eran todos españoles: altos funcionarios y políticos que hablaban de posicionarse de cara a tocar el tema en profundidad y en solitario. Por un momento creí haberme equivocado de reunión y estar en un congreso de pornógrafos pedantes, pero no, en esa sala caldeada se estaba hablando de política exterior y los participantes eran casi todos viejos amigos míos, gentes honorables y sensatas. Me había separado de ellos recién terminado nuestro paso por la universidad, los había dejado hablando en cristiano y ahora me los encontraba parloteando en una jerga incomprensible. Yo seguía entendiendo a la pipera madrileña o al gañán andaluz $-\mathrm{y}$ desde luego al campesino peruano o al peón costarricense- pero ya no entendía a mis pares, a la crema de la intelectualidad española. Callé, humildemente tomé notas, y de ese trabajo de campo, entre filológico y antropológico, nació el Guirigay Nacional.

Por tanto, el sentido 'lenguaje oscuro y difícil de entender', de los dos que indica el diccionario académico para guirigay, es el que motiva el título de la columna. Además, el autor dice explícitamente que sus "notas de campo" proceden del entorno de altos funcionarios y políticos, intelectuales, en el que se desenvolvía por su profesión. Como es sabido, el habla de los políticos se caracteriza por su oscuridad, por lo que su columna nos mostrará, como veremos, una descripción de los hablantes que frecuentaba, resultando un trabajo "entre filológico y antropológico", según él mismo lo define, esto es, estamos ante una aproximación sociolingüística a la lengua de los políticos.

En cuanto a Álex Grijelmo (Burgos, 1956), periodista y autor de obras de divulgación sobre lengua y comunicación, así como de libros de estilo para los medios, publica desde 2013 en el diario El País la columna titulada La punta de la lengua, que comenzó a escribir en 2000 para el suplemento semanal de un diario vallisoletano, como antes indicamos. En La punta de la lengua. Críticas con humor sobre el idioma y el diccionario (2004) se reúnen algunas de las columnas publicadas en el semanal y en su "Introducción" Grijelmo (2004, p. 15) aclara que con ellas no pretende establecer normas ni decir cómo expresarse, sino generar debate. En cambio, más tarde, en su intervención en Cartagena de Indias (sede del IV Congreso Internacional de la lengua española), al reflexionar sobre las características de las columnas periodísticas del lenguaje, señala que, siendo habitual el humor o la ironía, sus planteamientos de fondo son severos, porque "tradicionalmente hemos creído que hablar sobre la lengua significaba establecer y respetar normas. Normas que, por otra parte, emanan del pueblo" (2007, p. 3). Además, indica como característica propia del género la crítica a los que usan el lenguaje como herramienta profesional (2007, p. 2), y esto es así en sus columnas, en las que con frecuencia cuestiona el habla de los políticos. Por consiguiente, consciente de que se mueve en el terreno de lo interpretable, de la opinión, Grijelmo habla de normas desvinculándose del cometido de establecer lo que es o no correcto, aunque, como hemos puesto de relieve en otro trabajo (Sánchez Manzanares, 2019a), suele adoptar un tono prescriptivo. Por otro lado, otro propósito le guía; como hemos indicado anteriormente, una intención latente en sus columnas es prevenirnos para que las manipulaciones no modifiquen nuestra percepción de la realidad. 
Pardo (2012, p. 43) hace notar que, desde que se iniciaran los estudios críticos del discurso, el análisis micro-discursivo focaliza en el conjunto de recursos y estrategias "que permiten deconstruir el discurso como una expresión en la que se articulan sistemas sígnicos para producir significados". En el enfoque político de estos estudios, el objetivo es interpretar cómo se produce la expresión de relaciones de poder en los discursos producidos por las élites políticas (Pardo, 2012, p. 43). A continuación, analizamos una serie de columnas de uno y otro autor que hemos seleccionado como representativas de temas centrales en el análisis del discurso político con relación a recursos y estrategias de significación.

\subsection{CSL del Marqués de Tamarón: análisis y resultados}

La invectiva de Tamarón en sus columnas se dirige, en su mayor parte, a la clase culta, por ser el uso "torcido" de la lengua por parte de aquellos que tienen voz pública (políticos y periodistas) lo que motiva la degradación del español. Así se corrobora en la reseña que hace de una de sus propias conferencias, que firma como Santiago de Mora-Figueroa, publicada el 9 de diciembre de 1985 en $A B C$ :

1) [en la conferencia] se analizó la degradación que sufre el español como consecuencia no de los neologismos, siempre que estos sean inteligibles y útiles, sino de la comprensión torcida del lenguaje y su función por parte de políticos y periodistas.

En esta reseña, se cita a sí mismo indirectamente, reproduciendo fragmentos de lo que dijo:

2) "Hablar bien no consiste en ser redicho, sino en expresarse con llaneza y precisión", afirmó [Tamarón] que existe en la clase culta una especie de vergüenza a hablar correctamente y con propiedad.

En la CSL que titula: "Catapulta en clave de futuro" (6/12/1986), reputa el habla de políticos de papiamento, que define en los siguientes términos:

3) [...] papiamento (de papear, "hablar confusamente"), jerga pobre y borde que, contra lo que cree el Diccionario, ya no se habla en el Caribe sino entre burócratas, políticos $\mathrm{y}$ periodistas madrileños.

Insiste en esta descripción en su siguiente columna, "Cotorras” (13/12/1986):

4) El papiamento que estos [los políticos] hablan es tan oscuro y a la vez aburrido (salvo cuando caen en los tacos, lo único que se les entiende), que preferiríamos oír sus ruidos patrióticos del revés: resultarían del todo ininteligibles.

Este hablar del revés ${ }^{6}$ sería mejor, en su opinión, que su "media lengua de cotorras". Enfatiza en esta CSL la denigración de la lengua por parte de los políticos con sentencias como: "Las barbaridades que los políticos hacen con nuestro idioma sólo son comparables a las que hacen con nuestro dinero"; y la apoya con un argumento de autoridad: "El letrado de las Cortes Generales, Luis María Cazorla, en su libro La oratoria parlamentaria, termina probando que no existe tal oratoria en la actualidad, pues se desprende del libro la ignorancia y pedantería de los políticos". A propósito de la oratoria en España, aunque pudiera atribuirse su decadencia al régimen franquista, eso no explicaría, a su parecer, que cada día

${ }^{6}$ Introduce esta idea al hilo de su comentario sobre la emisión en Radio Pequín de los boletines de noticias en ruso al revés (reproducían la cinta desde el final). 
hablen peor abogados, opositores, periodistas; salva Tamarón, no obstante, a mirlos blancos como Leopoldo Calvo-Sotelo, de quien cuenta la anécdota en una librería, cuando reconoce los versos de Quevedo en El Parnaso español ("Buscas en Roma a Roma 'oh peregrino!').

En la CSL "Idiotismos de los políticos"7 (11/05/1985) afea el uso de una retórica incorrecta, especialmente cuando es deliberada para comprar votos con palabras, porque el español es de todos y los políticos "lo están devaluando tanto como la moneda con sus hipérboles y solecismos interesados". Describe la jerga de los políticos como parásito de nuestra lengua que, como tal, la corrompe, lo que le lleva a clasificar idiotismos según causas y fines, clasificación que comienza en esta columna y continúa en la siguiente, "Más idiotismos de los políticos" (18/05/1985). Finalmente, describe seis tipos de idiotismos: 1) los que buscan la anfibología interesada; 2) por dárselas de originales; 3) por obsesión sexual; 4) "yavalistas"; 5) por pedantería en la legislación; 6) para divertirnos. Ilustra cada tipo con varias expresiones, omitiendo la mayoría de las veces el nombre del político que cita, lo que no siempre hace. Así, en alguna otra columna dedicada a incorrecciones lingüísticas, como en "Premios de 1986" (03/01/1987) -en la que otorga premios a varios titulares periodísticos, pero en la que también introduce ejemplos del ámbito político- nombra explícitamente al alcalde de Madrid, Juan Barranco, por emplear desambular en lugar de deambular.

Además de su descripción del habla de los políticos como papiamento, por sus incorrecciones lingüísticas y retóricas incorrectas, lo más destacable en las CSL del Marqués de Tamarón sobre comunicación política es su caracterización de una determinada actuación verbal por la ideología política. En "Diestros y siniestros" (28/02/1987), como observa Guerrero (2019, p. 197), el Marqués de Tamarón arremete contra la censura lingüística que realiza la izquierda política, a la que presenta negativamente en un fragmento sesgado ideológicamente mediante una polarización (los "progres" frente a los otros). Por tanto, contrastamos su asociación entre conducta verbal y fracción política, en este caso, entre la censura lingüística y la izquierda.

Igualmente, en la CSL "Tabla rasa" (16/05/1987), en la que trata algunos neologismos, su intención es confrontar la actitud conservadora ante la lengua según el político sea de izquierdas o de derechas. Después de afirmar que la izquierda se caracteriza por hacer tabla rasa del pasado, juzga que tampoco a la derecha española le importa la conservación de nuestra lengua, en la medida que acepta innovaciones lingüísticas "interesadas" que dañan "la médula de sus intereses". Prueba de ello es que llama antimilitarista a los de izquierdas, cuando debería llamarles antimilitares ${ }^{8}$, porque "el más notable antimilitar fue un militarista,

\footnotetext{
${ }^{7}$ Comienza diciendo que analizará idiotismos en el sentido de 'ignorancia, falta de letras e instrucción' (como ejemplo da el uso de preveer en lugar de prever y el ornato innecesario a priori en una declaración en la radio del que era en aquellos años gobernador civil de Almería: "[los terremotos] son imposibles de preveer a priori"), pero después culpa a los políticos de idiotismos en el sentido de "modo de hablar contra las reglas de la gramática pero propio de una lengua" y así dice que el modo propio de la lengua de los políticos es una jerga contra las reglas de la gramática (Marqués de Tamarón, $A B C, 11 / 05 / 1985)$.

${ }^{8}$ Es frecuente que Tamarón ofrezca en su columna el significado "correcto" de los términos; aquí explica los sentidos de estos adjetivos: "Antimilitarista es hoy el calificativo universalmente aceptado -incluso por los que defienden a los militares- para definir a quienes los atacan. Pero esa aceptación es un error lingüístico y una torpeza histórica. Antimilitarista es quien se opone al militarismo («preponderancia de los militares, de la política militar o del espíritu militar en una nación», es decir
} 
Adolfo Hitler, un cabo resentido que odiaba a la casta de los oficiales". En este punto, hace una apreciación lingüística:

5) Es natural que los de la melena y la jeringuilla se llamen a sí mismos antimilitaristas, pero los demás somos tontos si aceptamos el matute semántico.

Así, denuncia un matute semántico, esto es, un sentido oculto, "clandestino", lo que también observa en la sustitución del término nacional-socialismo por el de nazismo, que considera una "abreviatura vergonzante" y ello porque, aunque el propósito sea "alejar la palabra socialismo de una aventura criminal", el hecho histórico que, en su opinión, no hay por qué olvidar es que el partido de Hitler se llamaba Partido Nacionalsocialista de los Trabajadores Alemanes. Por otro lado, señala que llamar primera dama a la esposa del presidente de Gobierno, además de ser barbarismo (por imitación de First Lady en los EE.UU.) y cursilería, es ilegalidad porque "este país tiene una Monarquía y si alguien es primera dama será Su Majestad la Reina". Termina la columna diciendo que estos desmanes no se deben al masoquismo de la derecha ni a la tabla rasa de la izquierda, sino a la tontuna general.

Lo que más enerva al Marqués de Tamarón es la falta de rigor lingüístico, el uso de voces imprecisas en la "jerga" de los políticos, a la que exige la exactitud que tienen la de matadores o marineros. De ahí su columna "De toreros, marinos y políticos" (20/07/1985), en la que la cuestión de la necesidad de los neologismos le da pie a introducir instrucciones sobre el conflicto entre la precisión y el cambio lingüístico, entre lo codificado y la adaptación al cambio social. Insta, en primer lugar, a dilucidar si el nuevo vocablo conviene y, seguidamente, a regular su uso, impedirlo mediante la burla o proponer una voz alternativa. Estima que esta tarea, que podrían asumir los formadores de opinión si no fuera por su sujeción a la moda, queda en manos de "escritores responsables, académicos o no", entre los que señala, entre otros, a Alvar, Seco, Cela, aunque alguna vez yerren (cita a Cela cuando escribe en solitario en lugar de a solas).

$\mathrm{Su}$ oficio de embajador y su cultura política le dotan de un conocimiento privilegiado para observar el habla de los políticos con relación a los cambios acaecidos en el orden social y político en España. Así, en su CSL "Excelentes y serenos señores" (23/11/1985), en la que trata fórmulas de tratamiento, escribe:

6) Lo paradójico del caso es que en un país como el nuestro, que, contra lo que creen los extranjeros, lleva un par de siglos desconociendo o desconfiando de sus raíces históricas, el Senado se acordase, al elaborar su reglamento en 1982, de una tradición del siglo XIX que hizo extensivo a todos los senadores el tratamiento de excelentísimo señor, en un principio reservado a aquellos que a la vez eran grandes de España. Pero lo cierto es que, gracias a su capacidad autonormativa, nuestra Cámara Alta se ha mantenido dentro de la legalidad al atribuir tantas excelencias a sus miembros. Más dudoso es el caso del Congreso, cuyos diputados parecen ser excelentes sólo por remedo de los senadores. Y lo más curioso es que los demás tratamientos que se dan en España suelen carecer de base legal sólida: se fundan en disposiciones antiguas de discutible vigencia o en la mera costumbre. Nadie ha pensado o se ha atrevido a hacer una recopilación completa y actualizada, como tampoco hay una norma general para las precedencias.

una perversión política del estricto espíritu militar) y antimilitar es quien se opone a lo militar o a los militares". 
A este saber por oficio se suma su saber lingüístico. En "Caprichos" $(01 / 08 / 1987)$ se acerca de nuevo a los neologismos para posicionarse con respecto a lo efímero de nuevas palabras, de "caprichos" como la crème de la crème, demonizar, shandy y califas. A propósito de califas, habla de barones, dando el origen del uso de uno y otro neologismo semántico y señalando errores históricos en sus nuevas acepciones. Otro neologismo da título a su columna "Ajustes finos" (08/08/1987), en la que irónicamente sugiere emplear afinar en lugar de ajuste fino ("en el sentido de leve corrección o ligero cambio de rumbo de la política gubernamental") y que aprovecha para mencionar la falta de autocrítica de los políticos, o, dicho de otro modo, su falta de sinceridad:

7) A mí no me parece tan mal la expresión ajuste fino, pese al pitorreo general que ha acogido al neologismo. Podían los ministros haber recurrido al viejo verbo afinar (un instrumento o un aparato, que es tanto como templarlo), pero para eso tendrían que haber reconocido antes que estaban desafinados o destemplados. Y no podemos pedir ciertas sinceridades a los políticos.

No tarda en tratar otros neologismos en "«Ocultismo» y «glasnost»" (12/09/1987), derivando igualmente la columna en una apreciación sobre los engaños de los gobiernos como algo habitual. Después de abordar el habla snob de políticos y periodistas (a estos últimos, los llama despectivamente gacetilleros por preferir ocultismo a ocultación y glasnot ${ }^{9}$ a franqueza), concluye que prefiere los "viejos embustes, antiguos por soleares, con los que siempre nos han engañado las niñeras y los Gobiernos tradicionales". Como estamos mostrando, más que los nuevos usos en sí mismos, lo que provoca la crítica de nuestro columnista es su falta de precisión semántica o su cursilería y, generalmente, su discusión de algunos neologismos por incorrectos desemboca en la interpretación de la insinceridad de los políticos.

En "Nada nuevo bajo el sol” (07/02/1987), el Marqués de Tamarón nuevamente realiza una aproximación a los usos políticos del lenguaje con relación a la ideología de quien habla, como anteriormente vimos, pero en esta ocasión para advertir los errores que cometen otros que realizan esta misma asociación y etiquetan ideológicamente las palabras. Así, nos advierte de una asignación equivocada por parte del político socialista Yáñez-Barnuevo cuando atribuye a la derecha el uso de pérfida Albion (expresión anglófoba para referirse a Gran Bretaña, cuyo nombre conocido más antiguo era Albión):

8) Comprendo que para un hombre de izquierdas sea tentador creer que la muletilla la inventó alguien como Franco o, haciendo un esfuerzo de memoria, algún francés como Pètain. Pero acudiendo a un diccionario de citas se comprueba que la expresión perfide Albion fue acuñada en París y, 1793 por el Marqués de Ximénèz, amigo íntimo de Voltaire y progre como el que más.

Se ocupa también en esta CSL de un término como ultrasur, que compara con el creado por Marx, lumenproletariat ('al margen del proletariado'), porque ambos son usados para aplicarlos a grupos que, en realidad, representan ideas contrarias a las que se significan en la etiqueta.

\footnotetext{
9 Indica que glasnot es un término importado del ruso con motivo de la política reformista de Gorbachov y cita un artículo del Economist (13/06/1987) en el que se explica su formación (glas 'voz' > golos 'voto'; nost. sufijo para construir nombres abstractos) y se da cuenta de que se recogía ya en el diccionario de 1790 de la Academia Soviética de Ciencias con el sentido 'disponibilidad a la discusión pública'.
} 
En "Moral y moralina" (22/03/1986) se acerca a otro tema que ha recibido gran atención en el análisis del discurso político: el uso de las llamadas palabrassimbolo ${ }^{10}$ :

9) Lo curioso es que este empobrecimiento del vocabulario moral realista ha ido parejo con el uso creciente de términos morales abstractos en la vida pública. Nunca como ahora se habló tanto, desde la extrema izquierda hasta la extrema derecha, de ética, honestidad (sic, porque se rehúye el término concreto que sería honradez o integridad), pluralismo, patria, honor. Pero en llegando el caso práctico se seca la inspiración lingüística y empiezan la vaguedad y la confusión. No nos atreveríamos a sacar conclusiones de tan paradójica evolución, pero sí a citar algunos ejemplos.

Entre esas palabras concretas que cita (frente a las abstractas, como patria), encontramos eufemismos (cesado por destituido), incorrecciones (el calco francés de boca a oreja), incluso un pleonasmo:

10) Cuando reina la desconfianza hay que convencer a golpe de pleonasmo. Don Antonio Pedrol Rius nos asegura («Ya», 6-3-86) que nunca trató con el ministro de Justicia de proyectos políticos de futuro. Pues iiban a ser proyectos de pasado?

En "El tonto español" (29/11/1986) examina vocablos del español para tipos de 'tonto' y ofrece una clasificación según la ideología política; así el tonto priado (o apriscado) $)^{11}$ es el de izquierdas, el apolítico o de centro es un zorrocloco ${ }^{12}$ y el conservador es un listo sin estimativa ${ }^{13}$. Aquí introduce más una caracterización sociológica que lingüística de los tipos políticos, aunque no desaprovecha la ocasión de mencionar la retórica revolucionaria de los tontos "priados" o subrayar expresiones propias de los "listos sin estimativa".

Por último, con respecto a políticas lingüísticas, en “¿Ise, oé?” (20/06/1987) comenta el Marqués de Tamarón una noticia de La Vanguardia (19/05/87) en la que se da cuenta del voto a favor de todos los diputados autonómicos andaluces para promover "el uso y prestigio de las hablas andaluzas", evitando su "discriminación frente al modo norteño de la lengua castellana". Su postura puede deducirse del sofisma con el que comienza la columna: ¿Ha dejado usted de pegarle a su mujer, sí o no?, que considera una paráfrasis de otros habituales en el lenguaje político. A su parecer, el andaluz sólo se diferencia por su fonética y esto ha conducido a convertir en símbolo fenómenos cambiantes y accesorios, como la pérdida de la ese final en la pronunciación, dando por cierto algo falso.

\footnotetext{
${ }^{10}$ Fernández Lagunilla ([1999] 2014, p. 22) señala las palabras-símbolo como prueba de una relación inversamente proporcional que se establece entre connotación e indefinición del componente denotativo y observa que su carácter simbólico o emblemático viene determinado por su fuerte carga emotiva y la indeterminación denotativa por su uso estereotipado y su difícil comprensión (como es el caso de palabras abstractas relativas a la organización sociopolítica: estado, nación, pueblo).

${ }^{11}$ El Marqués de Tamarón juega con los sentidos de priarse ('corromperse una cosa') y apriscar ('meter el ganado en un aprisco o redil') para explicar, mediante una falsa segmentación, que comparten un falso formante: -pri- que identifica con las siglas de un partido político mexicano, el PRI: "En España los tontos aPRIados y los aPRIScados suelen ser de izquierdas, antiguos idealistas algo miopes que se han afiliado al nuevo Movimiento".

${ }^{12}$ Así caracteriza al zorrocloco en el espectro político el Marqués de Tamarón: “[El zorrocloco] es de los que diciendo "ande yo caliente, y ríase la gente" deja la política en manos que tarde o temprano le harán pasar frío. Acostumbra ser centrista o apolítico. Me enseñó la palabra cierto Ministro que fue de la Corona, nada bobo él".

${ }^{13}$ Después de aclarar que estimativa significa tanto 'buen juicio o criterio' como 'el instinto de conservación de los animales', iguala al listo sin estimativa con un tonto del bote y lo caracteriza como aquel que hace "brillantes análisis irisados de matices ideológicos" y que, siendo conservador, no conserva por carecer de instinto de conservación.
} 


\subsection{CSL de Álex Grijelmo: análisis y resultados}

Las primeras columnas de Grijelmo, escritas entre 2000 y 2002 en el suplemento de El diario de Valladolid, se recopilan junto a nuevos textos en La punta de la lengua. Críticas con humor sobre el idioma y el Diccionario (2004), libro en el que el columnista dedica un capítulo a los "politiquismos":

11) Los politiquismos guardan cierta relación familiar con los administrativismos. Por algo participan de la misma estructura de poder quienes elaboran las directrices y quienes las ejecutan como Dios les da a entender. También suelen levantar barreras. $\mathrm{Y}$ a veces buscan la manipulación de los subconscientes (Grijelmo, La punta de la lengua, 2004, p. 29)

Además de algunas incorrecciones, en este apartado recoge usos tramposos, como carné vasco, del que dice que su nombre más preciso sería carné falso:

12) El mundo próximo a ETA se ha inventado el "carné vasco". Y en el momento en que lo nombramos así y lo oponemos a "carné español" estamos siendo manipulados por las palabras (Grijelmo, La punta de la lengua, 2004, pp. 29-30).

Se trata, por tanto, de usos manipuladores. También valora como nombre engañoso escudo antimisiles: expresión seductora de Bush para significar una actitud pasiva en la guerra, siendo, por el contrario, que su sistema planifica armas de ataque, interceptación y respuesta. (2004, p. 33).

Otros politiquismos que recoge resultan de aplicar una técnica propia de la manipulación política como es la de conjugar términos antitéticos. Anteriormente, en La seducción de las palabras (2000) había explicado el éxito de las palabras seductoras que resultan de tal explotación semántica: se ajustan al principio de perdurabilidad de significados activados subliminalmente, que quedan latentes e influyen en la interpretación de forma no consciente (2000, pp. 128-129). De este modo analiza la seducción de crecimiento cero ${ }^{14}$ y crecimiento negativo:

13) Sabemos que es imposible crecer cero (crecer y no crecer al mismo tiempo), y que nadie puede entender cómo se crece (concepto positivo) negativamente. La razón humana puede llegar a analizar estas palabras y descubrir el engaño, pero la penetración de tales voces en el cerebro y en el subconsciente guarda todas las armas de la seducción. El sonido de los vocablos contradictorios "crecimiento cero" se percibe por el oído o por la vista, y a través de ellos accede al léxico mental, en cuyos circuitos neurológicos se activan independientemente los significados de "crecimiento" y de "cero". El resultado de la unión entre ambos términos ofrece un sentido racional: no se ha crecido. $\mathrm{Y}$ así lo percibimos con nuestro cerebro consciente. Pero el hecho de que se haya activado la palabra "crecimiento" adquiere una repercusión subliminal, seductora, un significado inconsciente, que despierta de su sueño con el sonido, que se activa y que no se llega a desactivar, que se despereza y se mantiene en vela, que derrama su perfume sobre la frase y que la impregna de modo que ya no se podrá reintegrar a su frasco (Grijelmo, La seducción de las palabras, 2000, p. 131).

En otros politiquismos trata lo que en realidad responde al fenómeno de interdicción lingüística, por ejemplo, al tratar alta tasa delictiva, que sustituye en el uso político al término delincuencia:

\footnotetext{
${ }^{14}$ Sobre el eufemismo crecimiento cero explica: "consigue unir un concepto positivo (crecimiento) con otro negativo (el no-crecimiento), para neutralizar el efecto de éste (y además se acude a un número que no es negativo exactamente: el cero)" (Grijelmo, La punta de la lengua, 2004, p. 40).
} 
14) Si no se explicitan estos términos no se debe a la casualidad. Los políticos en el poder no quieren que por nuestras mentes pasen conceptos como delincuencia, pobreza o gente sin trabajo (Grijelmo, La punta de la lengua, 2004, p. 31).

Otra técnica que denuncia es la polarización del uso de términos por parte de grupos para establecer diferencias con los "otros"; en este sentido, se sorprende de la apropiación de soberanistas por parte de partidos nacionalistas sin que los partidos constitucionalistas, también soberanistas, hayan mostrado oposición ( $L a$ punta de la lengua, 2004, p. 30). Apunta también el uso de elementos aparentemente inocuos desde el punto de vista referencial, como es el caso de la preposición desde, como recurso para marcar diferenciación: "Tal vez intentan con él establecer diferencias: yo se lo digo desde aquí (desde la sinceridad, por ejemplo) porque usted está allí (lejos de la sinceridad, en ese caso)" (La punta de la lengua, 2004, p. 34).

Por último, entre los politiquismos destacamos su observación de la tendencia entre los políticos a usar palabras que significan efecto, como actuación, cuando se están refiriendo a proyectos, obras o acciones aún sin culminar, falseando entonces lo referido.

En Palabras de doble filo. Avisos y antídotos contra engaños y calamidades (2015) recopila las columnas que ha escrito en La punta de la lengua de El País desde 2013 hasta la fecha de su publicación. En una entrevista ${ }^{15}$ concedida a elDiario.es por este libro, destaca los eufemismos cuando se le pregunta por la relación entre palabras y realidad (distingue entre eufemismos de significado y los de significante) y habla de su preocupación por los silencios, por lo que se omite. De este período, seleccionamos como columna representativa de su interés por la significación de lo no dicho "El ministro sí dijo lo que no dijo" (17/11/2013). En ella, analiza la declaración del ministro Montoro sobre los problemas del cine español, de la que se infería que juzgaba que se debían a su mala calidad, aunque no lo dijera. Para disculparse, el ministró argumentó: "No dije que tenía baja calidad, no utilicé ese calificativo", lo que Grijelmo interpreta como "mentir contando hechos verdaderos". Además seleccionamos "«Lo peor ha pasado», pero sigue ahí" (26/01/2014), dedicada al relato que hacen los miembros del gobierno de la época de la crisis y problemas sociales derivados (como los desahucios), representativa de sus avisos sobre las trampas del lenguaje. Nos muestra cómo Rajoy usa el pretérito para hablar de ajustes y problemas que continúan vigentes, o cómo Sáenz de Santamaría proclama que lo peor ha pasado cuando dice: "Todos los indicadores ven una recuperación económica que no sé si casa mucho con las protestas sociales". Y nos advierte:

15) Toda trampa del lenguaje alberga una parte de verdad, a fin de resultar creíble, y recoge palabras que evocan algo positivo para esconder con ellas lo perjudicial.

Como ha visto Helfrich (2019, p. 148), uno de los recursos más destacados en la argumentación que Grijelmo desarrolla en sus columnas es la deslegitimación moral por evaluación y comparación. Lo comprobamos ahora en distintas columnas publicadas después del recopilatorio de 2015. En la CSL "Perdón extracontable"

\footnotetext{
${ }^{15}$ En este enlace puede accederse a la entrevista: Álex Grijelmo: "Procuro escribir muchas veces 'quizás' o 'tal vez"” (eldiario.es), en la que habla de los silencios como modo de manipulación lingüística en cuanto "lo que se calla no porque se omita el mensaje entero, sino porque dentro de un mensaje se omite una parte. Como, por ejemplo, en el EGM [Estudio General de Medios]: se resaltan unos datos y se omiten otros, o en los resultados de una empresa..." (Grijelmo, elDiario.es, 24/02/2015).
} 
(22/01/2017) -con subtítulo extraído del cuerpo de la columna: "Importaba pronunciar esa oración; y se atendió tanto a tales términos que quizá se desvaneció la atención hacia los que venían después"-, se refiere al "Pido perdón" de María Dolores de Cospedal por el accidente del avión Yak-42 en 2003 en el que murieron 62 militares españoles que regresaban de una misión en Afganistán. La cuestión moral que introduce Grijelmo es la sinceridad de nuestros actos verbales, que, por otro lado, se ha señalado en los estudios lingüísticos como condición de fortuna de determinados actos de habla. Comienza la columna con una deliberación sobre cómo identificar si una disculpa es sincera según el enunciado que se construye: "Las palabras exactas que se eligen para pedir disculpas dicen mucho acerca de la sinceridad de quien las pronuncia y de la certeza que tiene de sus errores". Seguidamente, cuestiona la sinceridad de la disculpa y señala dos recursos de orden gramatica ${ }^{16}$ usados en la comunicación política para realizar una engañosa petición de disculpas. Como se anticipara en el título, además de esta intervención de Cospedal, en esta CSL se alude a otra expresión memorable, esta vez del que fuera tesorero del PP, Bárcenas, cuando en el juicio a propósito de la caja B del PP (financiación ilegal del partido) declara que se trataba de una "contabilidad extracontable" (caso Gürtel). Finalmente, concluye con una referencia a la largamente comentada "indemnización en diferido o simulada", con la que Cospedal se refería al prorrateo del finiquito de Bárcenas cuando el extesorero abandonó la formación política:

16) A partir de ahora, podría continuar la ministra y secretaria general ocupándose de algunos otros asuntillos, entre ellos el de la contabilidad extracontable. Eso sí, llamando a las cosas por su nombre; para que, aunque se trate también de una tardía petición en diferido, no parezca además un perdón en $b$ (Grijelmo, El País, 22/01/2017).

Nuestro periodista suele introducir nociones pragmáticas en sus columnas para evaluar estrategias de la comunicación política con fines manipuladores. Así procede en las que valora si se declaró o no la independencia de Cataluña tras el referéndum celebrado en esta comunidad en octubre de 2017, como en "Puigdemont no hizo al decir" (15/10/2017) y "Declaración de doble sentido" (5/11/2017). En la primera, en la perspectiva de los actos de habla, del decir como hacer, considera que Puigdemont no declaró la independencia porque usó el verbo asumir, verbo de dicción y pensamiento de cuyo uso no resulta una acción. En la segunda se centra en la explotación del doble sentido por parte de dirigentes independentistas durante el procès:

17) La última resolución aprobada por el Parlament "insta" al Gobierno catalán a "dictar todas las resoluciones necesarias para el desarrollo de la ley de transitoriedad jurídica y fundacional de la república". Por tanto, una vez más, no se declara la independencia, sino que se anima al Govern a que lo haga (Grijelmo, El País, 05/11/2017).

\footnotetext{
${ }^{16}$ Estos recursos son: 1) el uso del subjuntivo: "No es lo mismo «pido perdón por los errores que haya podido cometer» (subjuntivo) que «pido perdón por los errores que he cometido» (indicativo)"; 2) el uso de estructuras sintácticas condicionales («Pedimos disculpas por si alguien se ha sentido afectado por la noticia de la colaboración entre el Barça y Turismo de Cataluña», tuit de la Generalitat para disculparse por el eslogan Si sientes el Barcelona, sientes Catalunya en una campaña de Turismo) (Grijelmo, El País, 22/01/2017).
} 
El procès ha sido objeto de análisis también en su artículo "Diccionario de la seducción independentista", en el que examina expresiones recurrentes en los discursos del independentismo:

18) Las palabras que han sostenido las ideas básicas del independentismo catalán pueden constituir un Diccionario de la seducción mediante el lenguaje, una relación de vocablos y locuciones cuyos significados se han pulido desde hace años para acercarlos a los propios intereses aunque eso implicase alejarlos de su genuino sentido, que queda así oculto en la maniobra (Grijelmo, El Pais, 22/11/2017).

En este artículo analiza una sinécdoque engañosa ${ }^{17}$ que identifica en el "lenguaje nacionalista" y que consiste en usar Cataluña, España o el Estado (el todo, representado como cuerpo sólido) para nombrar partes (gobierno, justicia, prensa):

19) Muchos españoles no están de acuerdo con lo que hace "España", y sin embargo son incluidos en las acciones que desarrollan algunas de las partes que se integran en esa palabra (Grijelmo, El País, 22/11/2017).

Esta misma sinécdoque la había tratado anteriormente en la CSL titulada "El “encaje" de Cataluña en España" (04/10/2015), con subtítulo: "El léxico empleado en el debate incluye algunas figuras retóricas que muestran a esa comunidad como si fuera un cuerpo sólido", en la que analiza la metáfora "falsa" encaje, que también retoma en "Diccionario de la seducción independentista" (22/11/2017). Observa que mediante esta metáfora se trata a Cataluña como una pieza independiente de España que hay que encajar, lo que, en su opinión, conlleva el riesgo de trasladar esa metáfora al seno de la propia Cataluña, donde tendrían que "encajarse" independentistas con catalanes no nacionalistas, por lo que propone:

20) Si se buscara mayor precisión retórica, los que observan el problema desde una perspectiva independentista podrían mantener la metáfora, pero al revés: defendiendo el "desencaje" de Cataluña. Y quienes ven España y Cataluña en la misma pieza pero plantean cambios en sus leyes pueden sustituir el "encaje", si lo desean, por "el reacomodo del Estatut en la Constitución". O propugnar "un nuevo molde constitucional" que acoja una convivencia actualizada (Grijelmo, El País, 22/11/2017).

Un tema preocupante para Grijelmo, junto al de los eufemismos, es el de los lenguajes identitarios. A este fenómeno discursivo, que muestra en sus columnas con relación a movimientos políticos y sociales, dedica un extenso artículo de opinión en El País, precisamente con título: "Los lenguajes identitarios" y subtítulo: "Algunos grupos utilizan determinadas palabras no tanto por su significado como por su simbolismo":

21) En los lenguajes identitarios tal como los entendemos en este texto, determinadas palabras adquieren el papel de símbolos, funcionan como insignias que el hablante se pone en su solapa con la idea de mostrar que son "la verdad". (Grijelmo, El País, 24/04/2019).

\footnotetext{
${ }^{17}$ Otra sinécdoque manipuladora que analiza en este artículo es el uso de nosotros por parte de un grupo independentista para significar todo el pueblo de Cataluña: "En el lenguaje independentista, "nosotros" significa "el pueblo de Cataluña", mientras que el "nosotros" de Mariano Rajoy o de Pedro Sánchez no significa "el pueblo español". Así pues, en el lenguaje nacionalista se toma de nuevo la parte como representativa del todo, ocultando la porción de los catalanes que no se ve reflejada en ese "nosotros" (Grijelmo, El País, 22/11/2017).
} 
La idea central es que una decena de palabras repetidas con intensidad se convierten en un léxico identitario. Tras unas notas sobre el léxico del nazismo hitleriano y del fascismo de Mussolini, explica que el franquismo se apropió de palabras como patria, paz, caudillo, incluso del nombre España, lo que supuso que durante la transición la izquierda se resistiera a su uso y lo sustituyera por el término Estado. Da otros ejemplos de léxico identitario de partidos nacionalistas, de ETA, de Podemos y, finalmente, del feminismo ${ }^{18}$, centrándose especialmente en el uso de jueza. Al léxico identitario de Podemos dedica la CSL "El léxico seductor de Podemos" (30/01/2018), analizando el uso por parte de la formación de bloque monárquico, casta, círculos, confluencias, gente, Jefe del estado/Rey, Nueva política/Vieja política, PPSOE, presos políticos.

En "Un PSOE más PSOE” (05/03/2017), Grijelmo localiza en varios discursos de la que fue presidenta de la Junta de Andalucía entre 2013 y 2019, Susana Díaz, el uso de esas grandes palabras "en cuyo interior caben las ideas que cada uno de nosotros nos hayamos formado de sus significados, a menudo discrepantes". Irónicamente, el periodista declara su subjetividad ante la identificación de esta estrategia, y decimos irónicamente puesto que a continuación presenta hasta siete declaraciones de la política andaluza ${ }^{19}$ para constatar este recurso, entre ellas la que incluye la expresión que da título a la columna. ¿Y por qué esta columna dedicada a Susana Díaz? Porque en el contexto político lo relevante informativamente en ese momento era su disputa con Pedro Sánchez después de dimitir este en octubre de 2016, forzado por su propio partido, por no apoyar a Mariano Rajoy como presidente del Gobierno. Con motivo del $39^{\circ}$ Congreso federal del PSOE diversos medios se hacen eco de la rivalidad en el interior del PSOE; así, Isabel Morillo escribe: "A seis días de la cita con las urnas, no habrá verdad, sino posverdad, es decir, una construcción de los hechos realizada con la intención de ganar una batalla interna que está siendo desgarradora" ( $E l$ Confidencial 13/05/2017). Por tanto, Grijelmo se acerca a este enfrentamiento en el escenario político para observar las estrategias discursivas por las que optan los políticos para enmascarar lo que a todas luces está sucediendo. En este caso, la posverdad se construye, según observa Grijelmo, ocultando la información de lo que efectivamente está sucediendo tras grandes palabras.

Entre las características del lenguaje político, Núñez y Guerrero (2002, p. 42) señalan la relación directa entre los grandes temas políticos y la producción de léxico. En "Impuestos voluntarios" (08/01/2017), Grijelmo da cuenta del léxico generado con las medidas implantadas por el gobierno del PP durante la crisis económica y denuncia la manipulación de que lo obligatorio parezca voluntario cuando se usan austeridad o esfuerzo. Como bien observa, cuando una serie de palabras se imponen en la comunicación de un problema político, otros vocablos quedan desterrados, y así ocurre cuando los dirigentes piden un esfuerzo a los ciudadanos:

22) La palabra "esfuerzo" menudea en el léxico del PP. Los logros en la reducción de gastos y en el incremento de ingresos se deben al "esfuerzo" de los ciudadanos,

\footnotetext{
18 Entre los vocablos del lenguaje identitario feminista identifica patriarcado, heteropatriarcado, androcentrismo, sororidad, empoderamiento, género, jueza (Grijelmo, El País, 24/04/2019).

${ }^{19}$ Grijelmo, como suele hacer al analizar las declaraciones de los distintos políticos, incluye un hipervínculo para acceder a noticias donde se reproducen estas declaraciones y así procede en esta columna (El País, 05/03/2017).
} 
representados así como atletas que intensifican su entrenamiento o como empleados que aceptan horas extraordinarias. Sin embargo, ese esfuerzo del que se habla no supone un desempeño opcional y volitivo. Ese mal llamado "esfuerzo" equivale a resignación, daño, penuria, miseria y otras palabras que han sido expulsadas del vocabulario general (Grijelmo, El País, 08/01/2017).

En realidad, en esta CSL Grijelmo está tratando de nuevo los eufemismos ${ }^{20}$, aunque hable del "cambiazo" que nos han dado con austeridad cuando se está hablando de una "cercenadura de los derechos sociales que ha producido esta crisis". Quizás porque no sustituye a una concreta palabra interdicta, Grijelmo habla de "cambiazo" y no de concepto tabú. Lo que es indudable es su falsedad en el nivel semántico ("no se trata ya de prescindir de lo innecesario, sino de renunciar a lo imprescindible").

En "El termómetro verbal del PSOE" (09/10/2016), CSL en la que, como consta en el subtítulo, analiza palabras que miden los cambios en los conflictos internos de un partido, muestra cómo los políticos elaboran un discurso eufemístico mediante el uso de un léxico seleccionado y apoyado sobre directrices de comunicación del partido para orientarnos en la representación de los acontecimientos. Ese léxico seleccionado varía de una época a otra y Grijelmo hace un recorrido por los que han empleado los socialistas cuando han hablado de su división interna ${ }^{21}$.

En cuanto al habla de los políticos evaluada desde el punto de vista de usos incorrectos y usos neológicos innecesarios, encontramos una columna como "El dialecto se posiciona" (29/10/2017), en la que considera que el uso "dialectal" fijar posición está motivado por la tendencia de los políticos a usar palabras largas (estiramientos). Lo que nos parece reseñable de esta CSL es que, del mismo modo que el Marqués de Tamarón tachaba de jerga el habla de los políticos, Grijelmo la tilda de dialecto.

\section{Discusión de resultados}

Del análisis de las CSL del Marqués de Tamarón se desprende que su ideal de buen uso de la lengua no se sitúa en los hablantes "cultos", al contrario que se ha asimilado en la tradición normativa, y ello por su falta de llaneza, precisión, corrección, propiedad. En su opinión, el habla de los políticos degrada, corrompe, devalúa nuestra lengua. Como ha mostrado Martínez Egido (2019, p. 98), entre aquellas columnas en las que caracteriza a un mal hablante, las más abundantes son aquellas en las que se refiere al gremio de los políticos y de los periodistas.

El marqués de Tamarón muestra su disgusto por la falta de precisión semántica de los políticos y argumenta su crítica lingüística, bien acudiendo a la significación sistémica, bien a hechos históricos, de manera que su opinión resulta, de alguna manera, irrefutable, además de ser indicio de sus conocimientos y su alto nivel cultural. Aunque aplica la variable de la ideología política en su análisis de forma interesada mediante la selección de ejemplos, el resultado es una exposición

\footnotetext{
${ }^{20}$ De hecho, la columna comienza mencionando otros usos eufemísticos, como movilidad exterior por emigración en boca de Fátima Báñez en 2013, entonces ministra de Empleo, para referirse a la salida de jóvenes del país por la crisis.

${ }^{21}$ Señala los siguientes: sector (durante el franquismo, más tarde recuperado, como el adjetivo renovador); corrientes (en la transición); familias (para reparar el contenido 'separación' implícito en corrientes, que representa partes de un todo); tendencias; sensibilidades (en los noventa, con intención de reparar la connotación 'tendencioso' de tendencias); bandos (sembrada por Pedro Sánchez, de carácter bélico).
} 
convincente, por la veracidad que se presupone a las constataciones lingüísticas y las referencias históricas en las que basa su argumentación. En este punto, hemos de resaltar su capacidad oratoria, de la que destacamos, por un lado, un estilo caracterizado por la riqueza verbal, en definitiva, un habla culta que se contrapone a la pretendida habla culta de los políticos; y, por otro lado, su aptitud para la argumentación. Esto es, el Marqués de Tamarón escribe acorde con su idea de lo que es el buen uso de la lengua: sin afectación, con precisión y corrección, todo ello aderezado con una actitud irónica y devastadora con la lengua de los políticos gracias a su habilidad para argumentar. Por tanto, la responsabilidad que exige con respecto al uso de la lengua, la ejerce en sus columnas, lo cual nos parece loable, si bien, como sabemos, no solo se realizan "matutes" semánticos mediante usos impropios.

La aproximación al uso político de la lengua del Marqués de Tamarón adopta un enfoque "antropológico", más allá del análisis puntual que realiza, y un enfoque "sociológico". En primer lugar, tiende a observar la relación entre lengua y cultura y por ello el uso "incorrecto" que motiva su columna es solo punto de partida para apuntar, mediante datos históricos, confluencias culturales que le permiten argumentar su inconveniencia, despropósito o esnobismo. Y en segundo lugar, utiliza el juicio sobre la lengua para realizar una interpretación de caracteres políticos, sirviéndose de la ironía. Esto es, nos ofrece el perfil sociológico del político de acuerdo con su habla y viceversa.

En cuanto a Álex Grijelmo, presenta un enfoque desde la ética del lenguaje que gira en torno al encubrimiento y falseamiento que se produce en la comunicación política por eufemismos, silencios intencionados y usos retóricos tanto léxicos como gramaticales. Los eufemismos en la comunicación política han sido frecuentemente analizados en los estudios del discurso atendiendo a su función de ocultamiento del referente que no se quiere mostrar con toda su carga semántica. Casas (2012, p. 68) diferencia entre tabú de palabra, por bloqueo psíquico-interno del hablante, y la interdicción conceptual, de motivaciones externas (afectivas o asociativas), centrada más bien en el oyente. Los eufemismos políticos suelen ser resultado de una interdicción conceptual, que Grijelmo examina con relación a sus motivaciones intelectuales y emocionales para deshacer su ambigüedad. Estos eufemismos modifican nuestra representación del mundo y de ello nos advierte el columnista: el problema es que el auditorio los acepte como representación de lo ocurrido y crea lo que es una mentira. Por ello los recursos y estrategias que señala constituyen una forma de persuasión ilegítima: los destinatarios no reconocen las intenciones o consecuencias reales de las creencias o acciones defendidas por el manipulador.

Grijelmo ha reflexionado extensamente sobre el hecho de que se acepte como cierto un engaño construido mediante palabras "preparadas para la seducción, dirigidas al subconsciente" (2000, p. 127). En la medida en que podamos reflexionar sobre nuestro idioma, podemos defendernos de estos engaños y, en nuestra opinión, este es uno de los cometidos que se arroga el columnista cuando aborda la manipulación de palabras por parte de los políticos:

23) Los materiales con que se construyen los engaños parecen infinitos: tan extensos como la inteligencia humana, tan vastos como los vocablos cuyo significado podamos dominar. Los mecanismos de defensa de que pueda disponer una persona ante tales cargas de profundidad se relacionan directamente con su capacidad de reflexión sobre el lenguaje, con su propio dominio del idioma y con su educación. 
Pero también la capacidad de usar las palabras arteramente en el propio beneficio es proporcional a esos recursos (Grijelmo, 2000, p. 127).

Mencionamos anteriormente la deslegitimación moral en la argumentación que desarrolla Grijelmo en sus CSL. El mismo autor ha señalado que la veracidad es una cuestión ética que supone que lo normal en la comunicación es no mentir. Y afirma:

24) Lo "veraz" excluye el silencio manipulador, porque "veraz" implica decir la verdad: entendida esta palabra como la coincidencia entre lo que hay en la mente y lo que se transmite en realidad. Si se omite algo relevante, ya no se produce esa coincidencia (Grijelmo, 2012, p. 397).

La interpretación de Grijelmo de la palabra como símbolo en el léxico identitario continúa la tradición del método lexicológico palabras e ideas que, como señala Rebollo (2002, p. 21), inaugura Matoré en La méthode en lexicologie (1953) y permanece hasta hoy ${ }^{22}$. Por otro lado, hemos visto cómo muestra que la comunicación política que llevan a cabo los gobiernos de turno corresponde a las distintas circunstancias políticas, económicas y sociales relevantes en el momento; también cómo muestra que esta comunicación responde a las directrices de comunicación marcadas por el partido. Todo ello no puede hacerlo sin poner en perspectiva esas circunstancias, esto es, Grijelmo no puede sustraerse a la evaluación de la actividad política que se comunica. En este sentido, pero en una perspectiva distinta a la del Marqués de Tamarón, nos muestra un perfil del político implicado, sobre todo cuando sitúa el foco en la ética.

Por último, en las CSL de Grijelmo, como nos dice Santamaría (2019, p. 245) se percibe "cierta nostalgia ante la pérdida de ciertas expresiones genuinas, propias del español, sobre todo por la entrada de extranjerismos". Esta nostalgia se deriva de su ideología lingüística acerca de la unidad del español, como expusimos en otro trabajo (Sánchez Manzanares, 2019a). La misma nostalgia trasluce en las CSL del Marqués de Tamarón, igualmente defensor de la ideología nacionalista de preservación del español frente a la degradación y corrupción de los neologismos introducidos por la clase política.

\section{A modo de conclusión y algunas cuestiones abiertas}

Dada la función interpretativa de la columna de la lengua, en cuanto género de opinión, y partiendo de la hipótesis de que en las dedicadas a la comunicación política los distintos autores tratarían los mismos recursos y estrategias señalados en los estudios del discurso, nos preguntamos al comienzo por la perspectiva o enfoque que adoptaría cada uno en su aproximación y por el propósito de su análisis. Seleccionamos al Marqués de Tamarón y Álex Grijelmo, dos columnistas que escriben después de la transición, pero separados por unas décadas, y confirmamos nuestra hipótesis en nuestro análisis de sus columnas, al tiempo que llegamos a establecer, en la discusión de resultados, su distinto enfoque y sus coincidencias y diferencias ante la evaluación del habla de los políticos. Nos ocupamos ahora de

\footnotetext{
22 Anteriormente, Matoré había propuesto, junto con Greimas, una clasificación ideológica del vocabulario de cada época con ayuda de las mots-témoins: palabras que caracterizan el estado moral, intelectual, económico, técnico, de la sociedad (por ejemplo: lumiéres, civilisation, sensible, para la época de 1700; humanitaire, individualisme, utilitaire, para los años 1830-1835) (Matoré y Greimas, 1948, p. 417).
} 
concluir acerca del propósito que guía las columnas que dedican a este tema y, al hilo de esta conclusión, plantearemos algunas cuestiones que quedarán abiertas.

En la comunicación política se pone de relieve la forma en que las élites interactúan con la sociedad, se evidencian las relaciones de poder a través de discursos cuya finalidad es el control ideológico y la influencia sobre la acción de la ciudadanía. Es por estos fines que se abren paso recursos y estrategias manipuladoras. Nuestros dos columnistas observan la manipulación lingüística por imprecisión semántica como un ejercicio normalizado en el ámbito de la comunicación política. Tanto uno como otro insisten en la obligación de llamar a las cosas por su nombre y evitar la ambigüedad. Ambos lo argumentan mediante una desligitimación moral de la mentira, más explícita, quizás, en las columnas de Grijelmo (no se puede mentir haciendo trampas con el lenguaje, manipulando lo referido), pero igualmente palmaria en las del Marqués de Tamarón. En Grijelmo, además, esto supone una pérdida de fe en la política, extensible a cualquier esfera de lo social, como queda expreso en su CSL "Posverdad que sí" (24/12/2016):

25) La era posverdad designa este tiempo de falsedades del que tanto se ha beneficiado Donald Trump, entre otros. Ya no importan la verdad demostrable ni la noticia cierta, sino la activación de emociones y de reacciones inmediatas, para lo cual se aprovecha la abundancia de canales que carecen de verificadores.

También el Marqués de Tamarón se nos aparece como un descreído, como desengañado. A veces tenemos la impresión, por la erudición de la que hace gala, su habla culta y su talante irónico, que está realizando un divertimento crítico dirigido más al político que al lector común. Pareciera que su intención, más que crear opinión, fuera hacer partícipe de sus apreciaciones al propio político cuya habla ininteligible y pedante desacredita. No deja de posicionarse ante la mentira en política, solo que lo hace desde el descreimiento, como si asumiera que no pudiera evitarse, y se irrita más ante la imprecisión semántica en cuanto incorrección que degrada la lengua. Por ello no comparte el cometido de Grijelmo de prevenirnos sobre la manipulación y dotarnos de recursos para defendernos, al menos no muestra de forma explícita esta intención. Ello tiene que ver, a nuestro parecer, con las décadas que los separan, porque lo cierto es que Grijelmo escribe en la época de la posverdad. En cualquier caso, los dos son creadores de opinión pública, cada uno en el periodo político en el que escribe.

Lo que nos preguntamos en este punto, en primer lugar, es por el interés previo del ciudadano por la corrección del habla de los políticos o por los recursos que emplean para la manipulación. Ciertamente, está preocupado por la mentira en política, pues se siente engañado cuando defraudan las expectativas que se ha forjado a partir de promesas electorales y compromisos gubernamentales. Nos inclinamos a pensar que, en la mayoría de las ocasiones, el interés de los ciudadanos por la lengua política surge a partir de la discusión pública de la clase política, que, en el seno mismo de su discurso, confronta los usos opacos y mentirosos del rival. De esta discusión se hacen eco los diarios y contribuyen con ello a la generalización de usos engañosos, como decíamos al inicio. En segundo lugar, nos preguntamos hasta qué punto interesa la columna de opinión sobre la manipulación lingüística en política si no hay un debate social previo sobre el asunto al que atañen determinados usos. En la mayor parte de las columnas analizadas, especialmente las de Grijelmo, el interés viene dado por la polémica que suscitan actuaciones políticas frente a problemáticas del grupo social (económicas, territoriales, sanitarias, etc.) y frente a 
situaciones de confrontación ideológica. Por último, nos preguntamos si acepta el lector que es mentira lo que le señala el columnista, especialmente cuando existe debate sobre la veracidad de determinados acontecimientos. Aunque lo reconozca como autoridad en la materia y pueda recibir lo que es una opinión como saber incuestionable (Sánchez Manzanares, 2019b, p. 55), lo cierto es que entramos, en ese caso, en otro tema, el de la credibilidad periodística.

Sean cuales sean las respuestas, a nuestro modo de ver, estas CSL son efectivas en la medida en que nos alertan sobre estos modos comunicativos y despiertan la inquietud, también la curiosidad, ante los usos políticos. Además, la creencia inconsciente de que existe lo que la lengua nombra sustenta los engaños de los políticos, por lo que la insistencia de los columnistas en que hay que llamar a las cosas por su nombre nos parece que, por obvia que parezca, está más que justificada.

\section{Referencias}

1. Casas Gómez, M. (2012). De una visión léxica y pragmático-discursiva a una dimensión cognitiva en la caracterización extralingüística y lingüística del eufemismo. En M. Bonhome, M. de la Torre y A. Horak (eds.), Études pragmaticodiscursives sur I'euphémisme/Estudios pragmático-discursivos sobre el eufemismo (pp. 53-72). Frankfurt, Peter Lang.

2. Chamizo Domínguez, P. J. (2004). La función social y cognitiva del eufemismo y del disfemismo. Panace@, vol. V (15), pp. 45-51. Recuperado de:

http://tremedica.org/panacea.html

3. Charaudeau, P. (1997). Le discours d'information médiatique. La construction du miroir social. Paris, Nathan.

4. Fernández Lagunilla, M. ([1999] 2014). La lengua en la comunicación política II: La palabra del poder. Madrid, Arco Libros.

5. Gallardo Paúls, B. (2014). Usos políticos del lenguaje. Un discurso paradójico. Barcelona, Anthropos.

6. Grijelmo, Á. (2000). La seducción de las palabras. Madrid, Taurus.

7. Grijelmo, Á. (2004). La punta de la lengua. Críticas con humor sobre el idioma y el diccionario. Madrid, Aguilar.

8. Grijelmo, Á. (2007). Intervención en Cartagena. Donde dice..., 8, pp. 1-3. Recuperado de: http://www.fundeu.es

9. Grijelmo, Á. (2015). Palabras de doble filo. Avisos y antídotos contra engaños y calamidades. Barcelona, Espasa.

10. Guerrero Salazar, S. (2019). Las CSL en la prensa española de los 80. Mujeres y feminismo. En C. Marimón (ed.), El columnismo lingüístico en España desde 1940. Análisis multidimensional y caracterización genérica (pp. 185-207). Madrid, Arco Libros.

11. Helfrich, U. (2019). De galicismos "bajo sospecha" y anglicismos "depredadores". Ideologías lingüísticas en textos metadiscursivos. En C. Marimón (ed.), El columnismo lingüístico en España desde 1940. Análisis multidimensional y caracterización genérica (pp. 135-158). Madrid, Arco Libros.

12. Marimón Llorca, C. (2019). Introducción: Las columnas sobre la lengua (CSL), un espacio discursivo para hablar de la lengua en la prensa. En C. Marimón (ed.), El columnismo lingüístico en España desde 1940. Análisis multidimensional y caracterización genérica (pp. 7-25). Madrid, Arco Libros.

13. Martínez Egido, J. J. (2019). Las CSL como discurso argumentativo: El caso del mal hablante. En C. Marimón (ed.), El columnismo lingüístico en España desde 1940. Análisis multidimensional y caracterización genérica (pp. 79-104). Madrid, Arco Libros.

14. Matoré, G. y Greimas, A. J. (1948). La Méthode en Lexicologie: A propos de quelques thèses récentes. Romanische Forschungen, vol. 60, 3, pp. 411-419.

15. Núñez Cabezas, E. A. y Guerrero Salazar, S. (2002). El lenguaje político español. Madrid, Cátedra.

16. Pardo Abril, N. G. (2012). Análisis crítico del discurso. Conceptualización y desarrollo. 
Cuadernos de lingüística hispánica, 19, pp. 41-62.

17. Rebollo Torío, M. Á. (2002). Caracterización del lenguaje político. En D. A. Cusato y L. Frattale (coords.), Atti del XX Convegno Associazione Ispanisti italiani (pp. 11-36), vol. 2. Recuperado de: http://www.cervantes.es

18. Sánchez García, F. J. (2018). Eufemismos del discurso político. Las claves lingüísticas del arte del disimulo. Madrid, Visor.

19. Sánchez Manzanares, C. (2019a). La unidad del idioma y otras ideologías lingüísticas en las columnas sobre la lengua de Álex Grijelmo. En C. Marimón e I. Santamaría (eds.), Ideologías sobre la lengua y medios de comunicación escritos. El caso del español (pp. 235-253). Berlin, Peter Lang.

20. Sánchez Manzanares, C. (2019b). Las CSL como discurso normativo. Las ideologías del bien hablar. En C. Marimón (ed.), El columnismo lingüistico en España desde 1940. Análisis multidimensional y caracterización genérica (pp. 53-77). Madrid, Arco Libros.

21. Santamaría Pérez, M. I. (2019). "Baia Baja", ¿irreverencia o progreso?: Nuevas autoridades en las CSL del siglo XXI. En C. Marimón (ed.), El columnismo lingüístico en España desde 1940. Análisis multidimensional y caracterización genérica (pp. 231257). Madrid, Arco Libros. 